\title{
THE CARROT AS FOOD
}

\begin{abstract}
THE 'King of Vegetables', as it is called in East Anglia, is easily grown and stored. It is universally liked, especially by children. Cooking, by a variety of methods, presents no difficulty, and the preliminary cleaning may be confined to a thorough scrubbing. The roots contain 10-15 per cent of solid matter, much of which is sugar. The green tops are rich in ascorbic acid, the antiscorbutic vitamin $C$, and may be used instead of parsley in making white sauce.
\end{abstract}

\section{Carotene as Provitamin A}

The particular value of the carrot as a food, however, arises from its property of accumulating in its root large amounts of the intensely yellow, fat-soluble hydrocarbon carotene, $\mathrm{C}_{40} \mathrm{H}_{56}$. This pigment, which occurs in several isomeric forms, is found with the xanthophylls, $\mathrm{C}_{40} \mathrm{H}_{54}(\mathrm{OH})_{2}$, in all green and in most yellow plant tissues, but is virtually absent from the roots of such common British vegetables as the parsnip, turnip, swede and radish. Potatoes are negligible as a source of carotene.

When foods containing carotene are eaten by animals small quantities are sometimes transferred to the body fat in an unchanged state. Carotene is thus mainly responsible for the yellow colours of butter fat and human blood serum. This transference of unchanged carotenoids, however, shows remarkable, and so far unexplained, variations between species. Carotene is present only in small amounts in egg yolk, the main pigment being xanthophyll. The fats of some animals, including the pig, sheep and rat, are colourless. In all vertebrate animals, however, most of the carotene absorbed from the alimentary tract is converted into vitamin A. This latter substance, exclusively an animal product, is a colourless unsaturated alcohol with a molecular weight of about half that of carotene.

\section{Vitamin A Deficiency}

When the amounts of carotene and vitamin A are more than adequate for immediate needs, stores of the vitamin are laid down, mainly in the liver. In the adult human, these reserves usually represent about three months supply at a rate of expenditure equal to the reputed daily requirement. When the diet is low in vitamin $\mathbf{A}$ and carotene, however, the reserves are used up. An early effect of deficiency is night blindness', which is due to a reduction of the efficiency of the retina in adapting itself to vision in dim light. The recent discovery that the photo-labile pigment 'visual purple' consists essentially of a combination of vitamin A with protein provides a ready explanation of the association of defective dark adaptation with deficiency of the vitamin, although in the complex process of adaptation other factors must also be involved.

More prolonged deficiency of vitamin A, such as occurs frequently in Asiatic countries, leads to the characteristic eye lesion 'xerophthalmia' and also severe skin abnormalities, such as 'toad-skin'. It is important to note, however, that in experimental animals the effects of vitamin A deficiency may be very varied, and that sometimes death may intervene before xerophthalmia or other outward sign of deficiency is developed. The infrequency of visible lesions cannot, therefore, be accepted as an assurance of universal adequacy of the vitamin A intake of the population of Great Britain.

The association of vitamin A with resistance to infection still constitutes a difficult problem. It is quite clear that, in the experimental animal, vitamin A deficiency leads to reduced resistance of the mucous membranes to bacterial invasion. No positive proof of the importance of vitamin A deficiency in the etiology of common infective diseases in humans, however, seems to be available.

\section{Vitamin A ReQuirement of Man}

After reviewing the available evidence, a Technical Commission of the League of Nations, sitting in 1937, assessed the vitamin A requirement of the human adult at about 3,000 I.U. per day (l I.U. $=0.6$ microgram of $\beta$-carotene). A more recent careful estimate by German workers places the requirement at 2,500 I.U. of preformed vitamin A, or 5,000 I.J. of carotene in oily solution, the difference being due to the inferior ability of man in using carotene as opposed to the rats employed in calibrating vitamin A against the carotene standard. In practice, of course, the vitamin A requirement will not be obtained exclusively as either preformed vitamin A or carotene, but as a mixture in which the former will be represented mainly by milk, butter, eggs and liver, and the latter by green vegetables, carrots and some yellow fruits such as the apricot. 
It is obvious that in time of war there must be a general tendency for a reduction in supplies of the foodstuffs containing preformed vitamin A and of yellow fruits. The requirement must therefore be made up by including increased amounts of green vegetables and carrots. If we assess the daily intake of vitamin $A$ in milk and vitaminized margarine at about 1,000 I.U., then the equivalent of 1,500-2,000 I.U. of preformed vitamin A must be made up by vegetables.

\section{Carotene Content of Carrots}

No comprehensive study of the various factors affecting the carotene content of carrots has yet been made. Variety is undoubtedly important; the rather uncommon pale sorts cannot be recommended. In varieties which have the usual reddishyellow colour, the size of the root has an important bearing on the carotene content. Carrot seedlings have roots which are almost colourless. Tender young roots which are removed as thinnings in spring and prized as a delicacy contain substantial amounts of carotene; but the concentration is often less than half that attained in more mature plants. For ordinary mature carrots, a carotene content of 200 I.U. per gm. may be taken as typical. This value greatly exceeds the 10 I.U. per gm. typical of cabbage.

\section{EFficiency of Absorption of CAROTENe}

If the absorption and utilization of carotene were completely efficient, the part of the daily requirement which has to be provided as carotene could be supplied by as little as $10 \mathrm{gm}$. of carrots. As mentioned above, however, it has been found in Germany that even when carotene is given in its most readily assimilable form as an oily solution, the efficiency of utilization is only about half that of preformed vitamin A. On this basis about $20 \mathrm{gm}$. of carrots would be required.

A further complication arises from the difficulty with which carotene is absorbed by the intestines from vegetable tissues. Investigation of this point is not easy for various technical reasons, and it is readily understandable that poor agreement should be found between the results of different workers. As a provisional estimate, however, an absorption of some 20 per cent of carotene when ingested as raw or cooked carrot would seem reasonable. On this basis, about $50 \mathrm{gm}$. of carrots, or roughly 2 oz., would be needed to make up the daily requirement in the absence of other vegetables.

\section{National ReQuirement of CarRots}

In calculating the national requirement of carrots, allowance must be made for the substantial contributions to the carotene supply made by the various fresh green vegetables which succeed each other in seasonal rotation. The carrot, however, is available in plenty at most times, and can be introduced into the diet in many different ways. Thus it may be used as a 'second' vegetable with roast or boiled joints, may be included in soups and stews, or used in less familiar roles in salads or sandwiches, or for sweetening puddings. It might not be too much to expect the carrot to provide half the total carotene requirement over the whole year, with an allowance of roughly $1 \mathrm{oz}$. per head of the population per day.

At this level the place occupied by the carrot in the menu should be frequent, but not unduly prominent. In families with a particular liking for this vegetable, much larger amounts might be used with advantage. An allowance of $1 \mathrm{oz}$. per head daily is equivalent to about 400,000 tons annually for the whole population, without allowing for wastages in distribution and cooking.

\section{Storage and the Disposal of Surplus SUPPLIES}

In ordinary farming practice carrots may be readily stored in clamps. No change in carotene content is to be expected, provided the roots remain in sound condition. Canning also has no injurious effect, the carotene remaining stable even when the cans are kept for prolonged periods in tropical countries. In selecting carrots for canning, young spring carrots should not be chosen, even though their greater monetary value might appear better to justify the cost of canning. As stated above, the carotene content of mature carrots is much higher, while the differences in flavour of young and mature carrots after canning are slight.

As a further possibility, the drying of carrots might repay investigation. When dried under suitable conditions carrots retain much, if not all, of their original carotene, although the precise conditions required for stability remain to be defined. Dried carrots might be cooked in the usual way after soaking in water, or alternatively might be ground down to a fine meal. Dried carrot meal has a pleasant sweet taste, and might be valuable as a war-time constituent of cakes or biscuits. With the present scarcity of oranges the inclusion of a moderate proportion of carrot in marmalade has been suggested. 
Finally, one important point must not be forgotten. As mentioned above, considerable stores of vitamin A can be accumulated in the liver. An excellent way to dispose of any hypothetical surplus of carrots therefore would be to stimulate immediate consumption. The increased storage of vitamin A in the livers of the population would represent a real national asset. Not only would we be in a better position to withstand any shortage of vitamin A which might occur during the following months, but we would also probably benefit immediately by improved dark adaptation, with a corresponding reduction in road and other accidents occurring after 'black-out'.

\title{
FLORA AND FAUNA OF THE INNER AND OUTER HEBRIDES
}

\author{
By Prof. J. W. Heslop Harrison, F.R.S.
}

$\mathrm{I}^{\mathrm{N}}$ Nature of June 17, 1939, p. 1004, was published an account of King's College (University of Durham) Biological Expeditions to the Inner and Outer Hebrides, bringing the records of our results up to the end of 1938 . Since then the work has proceeded steadily, although not to completion; nevertheless, in view of present circumstances, it seems best to supply a similar summary of the fruits of our 1939 and 1940 investigations.

Despite obvious difficulties, we have spent considerable periods during those years on the Islands. Thus, in the late spring of 1939 we visited Mull, Coll and Tiree, continuing our work in summer by exploring Lewis, Great Bernera, Little Bernera, Harris, Berneray, Pabbay (Sound of Harris), North Uist, South Uist, Fuday, Fiaray, Barra, Muldoanich, Vatersay, Flodday, Sandray and Pabbay (Barra Isles). Similarly, in the early summer of 1940, we concentrated our efforts on Tiree, Coll and Gunna, returning later to Coll to examine more closely certain aspects of its flora, and then ending the season by exploring the Isles of Benbecula, South Uist and Colonsay.

As usual, both the flora and fauna of the islands were studied, but the plants proved the most productive of novelties. In particular, our researches have added greatly to our knowledge of the distribution of several important elements in the British flora: (1) those of boreal and alpine proclivities, (2) those of southern and southwestern origin, and (3) those of American affinities.

Before we commenced our work, the majority of species belonging to the first-named section was supposed, of necessity, to be restricted to the mountains of Lewis and Harris. Now it has been shown that a new 'focus' for such plants exists in the Beinn Mhor, Feaveallach, Hecla area of South Uist. Upon this more or less unglaciated mountain massif we have observed up to date, Thalictrum alpinum, Cochlearia alpina, Saxifraga oppositifolia,
S. stellaris, Oxyria digyna, Epilobium alsinifolium, Saussurea alpina, Salix herbacea, Alopecurus alpina, Deschampsia alpina, Poa alpina, Carex vaginata, $C$. rupestris, $C$. rariflora and $C$. rigida. In addition, we have detected there a second and very peculiar species of Epilobium with fleshy, characteristic leaves. This was not in flower when collected: nor have specimens brought home alive flowered since. Almost certainly the plant is the arctic Epilobium Hornemanni.

In extending the list of boreal and alpine forms, other Outer Islands have added their quota as, for example, Silene acaulis (Berneray and Mingulay), Cerastium arcticum (at a low elevation on Rueval, Benbecula), Oxyria digyna (Mingulay and Pabbay) Ajuga pyramidalis (Barra and Muldoanich), and Salix herbacea (Barra and North Uist). Of importance, too, is the fact that we have also collected Silene acaulis and Polygonum viviparum at sea-level at Uig in the west of Lewis and on Little Bernera off the same coast.

Furthermore, in spite of the low altitude of Coll, its rocky outcrops and sand dunes have been shown to support strong colonies of Saxifraga hypnoides, Ajuga pyramidalis and Carex rigida.

Of southern and south-western plants, Juncus capitatus has been taken on Barra, whilst not far away the muddy shores of Loch St. Clair have yielded Illecebrum verticillatum (a plant already recorded for Eriskay by Goodrich-Freer) to several members of our party. On Fuday we had the pleasure of seeing a single plant of Cicendia pusilla, whilst South Uist likewise produced the same plant, with Herniaria glabra var. ciliata in addition. In this connexion, too, we should like to emphasize the confirmation of the occurrence of Epilobium tetragonum in the Outer Isles, with the significant addition of $E$. Lamyi on Fuday and South Uist.

For its headquarters in the Hebrides, the 